\title{
EDUCAÇÃO E CIDADANIA: SEU PREPARO PARA O EXERCÍCIO DA CIDADANIA
}

\author{
Rosiele Rita Guimarães \\ Pós-Graduação em Ciências Ambientais - Instituto Federal do Triângulo Mineiro (IFTM) \\ rosiele.guimaraes@hotmail.com
}

\section{Resumo}

A cidadania é entendida como os direitos e deveres que os cidadãos têm no ordenamento jurídico e político. A população tem reconhecido o seu direito a uma educação básica de qualidade, mas alguns cidadãos não realizam esse direito. Entretanto, se as comunidades reconhecem esse direito é importante fator para a construção de uma comunidade de cidadãos, mesmo sendo esta cidadania considerada limitada. O presente artigo tem o objetivo de identificar a educação e ética na formação dos cidadãos. A metodologia utilizada para a pesquisa foi realizada através de referências bibliográficas, artigos e pesquisas realizadas. Os resultados alcançados aponta-se que a cidadania deve ser considerada como conjunto de valores, não só pelo fato de ser reconhecida, mas também concretiza em uma realidade na vida dos indivíduos cidadãos. Sendo assim, a democracia é considerada como uma construção de todo o valor, os indivíduos que aderem a ela devem atribuir-lhe sentido e devem inventa-la de modo que faça digna de reconhecimento.

Palavras-chave: Cidadania. Ética pública. Educação. Democracia.

\section{EDUCATION AND CITIZENSHIP: HIS PREPARATION FOR THE EXERCISE OF CITIZENSHIP}

\begin{abstract}
Citizenship is understood as the rights and duties as citizens have the legal and political system. People have recognized their right to a quality basic education, but some people do not realize that right. However, if communities recognize that right is an important factor for building a community of citizens, even if that citizenship considered limited. This article aims to identify the education and training of citizens in ethics. The methodology used for the research was qualitative, through references, articles and searches made. The results achieved it is pointed out that citizenship should be considered as a set of values, not only by being recognized, but also embodies a reality in the lives of individuals citizens. Thus, democracy is seen as a construction of all money, individuals who adhere to it should give it meaning and must invent it so that it makes worthy of recognition.
\end{abstract}

Keywords: Citizenship. Public Ethics. Education. Democracy. 


\section{Introdução}

O presente tema "educação é cidadania" são conceitos que têm longa tradição histórica, apesar de eles manterem alguns elementos básicos recorrentes em seus significados, as concepções sobre os mesmos variam de acordo com as circunstâncias de tempo e lugar:

[...] uma primeira ideia que se enfatiza é a de que eles devem ser entendidos como processos de conquista, como construções permanentes e não meras noções, puras, abstratas. Iniciando pela cidadania, ela encontra raízes na antiga Grécia, nas elaborações sobre a democracia, da qual faz parte ou está intimamente associada. A ideia de participação na polis, do homem político, já apontava para a concepção moderna de cidadania. (WANDERLEY, 2004, p.127).

O presente artigo tem como objetivo identificar o processo de educação e cidadania, a fim de discuti sobre a ética pública, considerada como um fator para exerce a educação e a cidadania. O presente estudo justifica-se ao tema "Educação e Cidadania", no desenvolvimento do estudo identificou-se que é fundamental a educação democrática de todos os indivíduos.

A origem mais reconhecida deriva das lutas e do imaginário presente na Revolução Francesa. Dessas fontes, pode-se extrair um primeiro sentido geral de que cidadania significa um conjunto de direitos e deveres, os atributos essenciais que a caracterizam estão centrados nas noções de público e civismo.

Segundo o entendimento de Wanderley (2004), para que os direitos conquistados sejam concretizados:

\footnotetext{
Requerem- se garantias que assegurem o seu pleno exercício, mecanismos jurídicos que os tornem efetivos, e, desse modo, historicamente, eles têm sido fixados em leis e constituições, nas distintas nações. Por isso, na teoria constitucional, eles são pensados a partir de seu vínculo jurídico com o Estado. (WANDERLEY, 2004, p.127, grifo do autor).
}

Entretanto, a educação tem como finalidade a construção da cidadania e precisa ter uma base forte de ética e moral. Na educação pode ser refletida aos modos dos cidadãos em que reconhecem os seus direitos políticos e jurídicos.

O referencial teórico foi aprofundado em especial a partir das teorias do autor Gentili, em sua obra "Educar na esperança em tempos de desencanto", e também contou com a bibliografia de outros autores.

A presente pesquisa foi dividida em três seções, tendo a presente introdução, o referencial teórico conceituando o tema "Educação e Cidadania" para melhor entendimento e 
as considerações finais, que poderá ser utilizada em futuras pesquisas desenvolvidas a fim de discutir sobre a educação e cidadania.

\section{Educação para o Exercício da Cidadania}

Sobre cidadania o dicionário de língua portuguesa Larousse afirma ser "qualidade de cidadão", "qualidade de uma pessoa que possui, em uma determinada comunidade, política, o conjunto de direitos civis e políticos".

No entanto, na realidade em que vivemos atualmente, se indagarmos a respeito do tema, certamente encontraremos uma diversidade de opiniões e nenhuma definição que possa contemplar de forma plena o conceito de cidadania. Podemos afirmar que ser cidadão é ter direitos e deveres. Mas de que maneira poderemos definir quais direitos e quais deveres? Portanto, é na determinação destes direitos e deveres que se encontra o "nó" relacionado a esta questão complexa que é a cidadania. (ARAUJO, 2013).

"Temos sustentado que definir a cidadania desde e a partir dos direitos que formalmente constituem é, embora importante, uma visão profundamente limitada e arriscada em matéria de política". (GENTILI, Pablo. 2007. p. 86).

Os cidadãos são aqueles que participam de uma mesma comunidade política, possuem os mesmos direitos e deveres, o reconhecimento jurídico de determinado benefícios comuns conseguiria igualar politicamente os membros de determinada comunidade. (GENTILI, Pablo. 2007. p. 87, grifo nosso).

Portanto, a população tem reconhecido o seu direito a uma educação básica de qualidade, mas alguns cidadãos não realizam esse direito. Entretanto, se as comunidades reconhecem esse direito é importante fator para a construção de uma comunidade de cidadãos, mesmo sendo esta cidadania considerada limitada.

A cidadania deve ser considerada como conjunto de valores, não só pelo fato de ser reconhecida, mas também concretiza em uma realidade na vida dos indivíduos cidadãos. Neste sentido, a construção de um conjunto de valores, de normas e de direito, que fazem dos indivíduos cidadãos. Sendo assim, a cidadania é a condição para a construção de uma sociedade democrática e igualdade.

A moralidade se constrói através da educação moral dos indivíduos: família, escolas igrejas, empresas, partidos políticos, meios de comunicação, sindicatos e todos aqueles âmbitos nos quais se estabelecem os vínculos socialização que, em variado grau e intensidade, 
influenciam na vida moral dos indivíduos. Assim, a moralidade se constrói através socialmente em todo o processo de formação humana.

De acordo com GENTILI, Pablo (2007. p. 88 -89, grifo do autor), dispõe que devemos reconhece que:

Os fatos morais, bem como as interpretações sobre os mesmos, possuem certo grau de contingência derivado de seu inerente caráter social. A moralidade e as formulações teóricas que a interpretam nada têm de inevitáveis, nem são produto de uma aparente essência humana (...). A aspiração e a vontade para fazer de determinada perspectiva moral um fator de reconhecimento comum por parte de indivíduos, grupos e comunidades devem partir do reconhecimento dessa questão fundamental. Atribuir a certo fato um valor implica dotá-lo de um significado relevante, pelo menos a partir da perspectiva de quem o enuncia (...). Uma sociedade democrática vale mais do que uma sociedade despótica e corrupta: a moralidade democrática faz do despotismo e da corrupção "verdadeiras" imoralidade.

O democratismo é considerado uma construção de todo o valor, os indivíduos que aderem a ela devem atribuir-lhe sentido e devem inventa-la de modo que faça digna de reconhecimento.

"Não há, portanto, nada essencial nos valores, nas normas e nos direitos que explicam e legitimam a cidadania. Nem tampouco na ética pública que deve fundamentá-la como práxis intersubjetiva”. (GENTILI, Pablo. 2007. p. 88, grifo do autor).

A educação para a cidadania, de projetos educativos voltados para a cidadania, enfim, de sociedades que tenham no cidadão o foco de suas preocupações. Mas apesar da discussão que é bastante amplo o que se pode perceber é que a literatura produzida não nos esclarece este aspecto importante para as sociedades ditas democráticas. Importante na medida em que, para que seja democrática, uma sociedade tem na participação dos seus indivíduos uma característica básica. (ARAUJO, 2013).

O desenvolvimento de uma ética que afirma e se fundamenta na igualdade, na democracia, na autonomia e na liberdade é o requisito indispensável para que a cidadania seja algo mais que uma (falsa) promessa. Uma ética pública que ensina os indivíduos que o único que á sustenta é o árduo trabalho cotidiano, a luta ousada por fazê-lo merecedora de vontades autônomas de cidadãos e cidadãs que aspiram construir e ser protagonistas de sua própria história (GENTILI, Pablo. 2007. p. 91, grifo nosso).

Por fim, sugerem-se algumas pistas de uma educação para a democracia:

a) oferecer um ensino de qualidade;

b) rever paradigmas, modelos, teorias e métodos, adequando-os ou recriando-os em função da realidade em construção; 
c) elaborar conhecimentos que integrem ciência e senso comum, que capacitem os educandos a serem pessoas competentes, democráticas, éticas e solidárias no combate à pobreza e à desigualdade;

d) potencializar experiências alternativas de publicização;

e) revitalizar a educação popular.

f) articular a escola com os meios de comunicação de massa;

g) estimular a autonomia e a flexibilidade nos modos de pensar e de agir, novos formatos institucionais e organizacionais;

h) ampliar a participação dos leigos nas mantenedoras e escolas confessionais. (WANDERLEY, 2004, p.134).

Para atingir esses desideratos, certas medidas são urgentes:

a) fortalecer os controles da sociedade civil sobre os organismos governamentais e sobre os conselhos de educação (nacional, estadual e municipal), na formulação das políticas educacionais, na sua organização e funcionamento;

b) nas universidades, estimular a participação ativa dos membros das comunidades em todas as instâncias internas e nas atividades de extensão;

c) colaborar nas estratégias de avaliação institucional das instituições de ensino superior, avaliação interna e externa, para assegurar a sua legitimidade na sociedade e o cumprimento dos seus objetivos maiores. (WANDERLEY, 2004, p.135).

A educação é um meio de construção e reconstrução de valores e normas que dignificam as pessoas e as tornam mais humanas. Numa educação ética, é preciso resgatar e incorporar os valores solidariedade, de fraternidade, de respeito às diferenças de crenças, culturas e conhecimentos, de respeito ao meio ambiente e aos direitos humanos. (SIEGEL. 2005.p 41, apud CABRAL, 2008).

Ser cidadão é perceber que fazemos parte do mundo. Nossas escolhas e posturas diante da vida afetam não apenas a nós mesmos, mas também a vida de outras pessoas, da comunidade. Assim como as atitudes das outras pessoas também nos afetam. Ao invés de só reclamarmos poder agir e transformar as coisas. É verdade que sozinhos não podemos mudar tudo, mesmo por que cada um de nós tem um ponto de vista diferente do que e de como mudarmos as coisas. Ter como princípio a valorização do humano, do ser e não apenas do ter material, já é um bom começo. Em nossas comunidades, escola, clube, prédio, rua, etc. Sempre há pessoas que se uniu para lutar por algo que acredita. (CABRAL, 2008).

“A democracia não se refere só à ordem do poder público do Estado, mas devem existir em todas as relações sociais, econômicas, políticas e culturais. Começa na relação interindividual, passa pela família, a escola e culmina no Estado. Uma sociedade democrática 
é aquela que vai conseguindo democratizar todas as suas instituições e práticas”. (Bóbbio, 2002 apud Cabral, 2008).

Ao tentar propor uma educação para a formação da cidadania elaboraram princípios pelos quais pode ser orientada a educação e que estão descritos no PCN e da Ética a seguir:

a) dignidade da pessoa humana, que implica no respeito aos direitos humanos, repúdio à discriminação de qualquer tipo, acesso a condições de uma vida digna, respeito mútuo nas relações interpessoais, públicas e privadas;

b) igualdade de direitos que refere-se à necessidade de garantir que todos tenham a mesma dignidade e possibilidade de exercício da cidadania. Para tanto há que se considerar o princípio da equidade, isto é, que existam diferenças (éticas, culturais, regionais, de gênero, etárias, religiosas, etc.) e desigualdades (socioeconômicas) que necessitam ser levadas em conta para que a igualdade seja efetivamente alcançada;

c) participação, que como princípio democrático, traz a noção de cidadania ativa, isto é, da complementaridade entre a representação política tradicional e a participação popular no espaço público, compreendendo que não se trata de uma sociedade homogênea e sim marcada por diferenças de classe, étnicas, religiosas, etc;

d) corresponsabilidade pela vida social, que implica em partilhar com os poderes públicos e diferentes grupos sociais, organizados ou não, a responsabilidade pelos destinos da vida coletiva.

De acordo com entendimento de Cabral (2008),

Educar para a cidadania é adotar uma postura, é fazer escolhas. É despertar para as consciências dos direitos e deveres, é lutar pela justiça e não servir a interesses seculares. É uma urgência que grita e que deveria ecoar nos corações humanos e não nos alarmes das propriedades que tentam proteger a vergonha do que a civilização humana construiu. Para alcançarmos isso, não podemos ficar somente no ensinar para a cidadania. É preciso construir o espaço de se educar na cidadania. E nesse sentido, não é somente a preposição que muda. Muda a postura do professor que de cidadão que somente exige seus direitos passa a lembrar de também dos seus deveres.

Segundo o entendimento de Almeida (2014), para analisar as atuais políticas públicas em educação é necessário estabelecer como marcos centrais a Constituição Federal de 1988 CF88 e a Lei de Diretrizes e Bases da Educação Nacional - LDB (Lei nº 9394/96). Nesse sentido, pode-se afirmar que:

O capítulo da educação na Constituição de 1988 é o mais detalhado de todos os textos constitucionais anteriores que, de uma forma ou de outra, trataram da educação no Brasil. A Lei de Diretrizes e Bases, por sua vez mantém o espírito da Carta Magna, detalhando seus princípios e avançando no sentido de encaminhar orientações gerais para o sistema educacional. A importância de conhecer a base legal decorre do fato de que esta, embora por si não altere a fisionomia do real, indica um caminho que a sociedade deseja para si e quer ver materializado (VIEIRA, 2006, p. 29 apud ALMEIDA, 2014, p. 2). 
"Resta claro que a própria Carta Constitucional determina que a educação seja um dever do Estado, da Família e da Sociedade que será efetivado, conjuntamente, visando à construção da cidadania e à inserção no mercado de trabalho.” (ALMEIDA, 2014, p. 2). O Art. 205 da Constituição Federal define a educação da seguinte forma:

Art. 205. A educação, direito de todos e dever do Estado e da família, será promovida e incentivada com a colaboração da sociedade, visando ao pleno desenvolvimento da pessoa, seu preparo para o exercício da cidadania e sua qualificação para o trabalho.

De acordo com Gohn (2009, p.36 apud Almeida, 2014, p.2) alerta que:

A escola pode ser pólo de formação de cidadãos ativos a partir de interações compartilhadas entre a escola e a comunidade civil organizada, e as lutas pela educação, o alicerce dessa nova história. A participação da sociedade civil nas lutas pela educação não é para substituir o Estado, mas para que este cumpra seu dever: o de propiciar educação de e com qualidade para todos.

“A Lei no 9394/96 - Nova LDB, apesar de surgir no Brasil num contexto político econômico de uma sociedade globalizada e neoliberal, traz em seu bojo o ideal de um sistema educacional mais democrático e inclusivo, mesmo esbarrando, em muitos momentos, nas limitações e entraves de ordem Financeira." (ALMEIDA, 2014, p.2).

O Estatuto da Criança e do Adolescente - ECA (Lei nº 8069/90) garante o acesso e a permanência das crianças à escola e possibilita, também, o acesso dos alunos, pais e professores à elaboração das propostas educacionais da escola. O Art. 53 do ECA determina o direito à educação, visando ao pleno desenvolvimento da pessoa, preparo para o exercício da cidadania e qualificação para o trabalho.

Para Oliveira (2006), o ECA conclama a sociedade civil, o Poder Público e a família para a responsabilidade de garantir o cuidado e a proteção infanto-juvenil, sendo um instrumento legal de grande importância para a preservação dos direitos e manutenção dos deveres das crianças e adolescentes brasileiros.

A educação pode ser entendida como um processo civilizatório que forma o indivíduo para a vida e para o trabalho, começando em casa com a família e prosseguindo na escola, a partir dos valores culturais da comunidade, segundo Xavier (2005).

Dentre os vários princípios que regem o ensino brasileiro, elencados no Art. $3^{\circ}$ da LDB/96, ressalte-se a importância da igualdade de condições para o acesso e permanência na escola, da valorização do profissional da educação escolar, da gestão democrática do ensino 
público e da vinculação entre educação escolar, o trabalho e as práticas sociais como indispensáveis para a construção da cidadania através da educação. (ALMEIDA, 2014, p.3)

As "reflexões sobre a Importância da Educação para a Cidadania: um enfoque prático do ser, do ser humano. Não é possível ser um ser indeterminado, como eu, somos conscientes dessa inconclusão sem buscar. E a educação é exatamente esse movimento de busca, essa procura permanente" (FREIRE, 2001, p.171, grifo do autor).

A importância da formação da cidadania no ambiente escolar é um tema que vem sendo atualmente discutido, como realizar a cidadania em um país com imensa desigualdade social.

Portanto, é nesse sentido que as lições de Paulo Freire e da Educação Popular ganhou força, evidenciando a íntima relação entre educação e cidadania, isto é, entre um processo que, por um lado, desenvolva aprendizagens para a compreensão da realidade em que vivemos é extremamente complexa, e que, por outro, permita a reflexão sobre as formas de intervir sobre ela. (DORNELLES et al., 2006, 104 apud ALMEIDA, 2014, p. 7).

Weffort (1995, p. 99 apud ALMEIDA, 2014, p. 7) entende que:

A escola que se abre à participação dos cidadãos não educa apenas as crianças que estão na escola. A escola cria comunidade e ajuda a educar o cidadão que participa da escola, a escola passa a ser um agente institucional fundamental do processo da organização da sociedade civil.

Segundo Araújo (2007 apud Almeida, 2007, p. 8), é ideal é que o entorno da escola se transforme em espaços de aprendizagem, de promoção e de garantia de direitos, deveres e da cidadania, rompendo os limites físicos dos muros escolares, incorporando os recursos da cidade e, prioritariamente, do entorno escolar.

Senso assim, pressupõe uma nova maneira de pensar o papel da escola, mudando de paradigma, revisando os papéis dos diferentes agentes educacionais e proporcionando uma abertura da escola para acolher a diversidade da população que a compõe, tornando-se, então, parte integrante da vida dos estudantes e da comunidade local.

\section{Considerações Finais}

A cidadania é apresentada em duas perspectivas: a primeira como condição legal e a segunda como atividade desejável. Como condição legal fala-se em cidadania civil, a cidadania política e a cidadania social. 
O contexto reflete que educar no âmbito da cidadania como condição legal tem o intuito de transmitir os direitos reconhecidos pelos cidadãos, o que diferencia com a ideia de educação na perspectiva da educação como atividade desejável, onde educar ultrapassa o simples reconhecimento dos direitos para alcançar a realização dos atributos que definem cidadania.

Contudo, a cidadania é muito importante para que as pessoas possam exercer seus direitos como um cidadão responsável e que exerce a cidadania, mas para isso é preciso reconhecer os seus direitos para poder desfruta-los. Sendo assim, nem todos sabem o que é cidadania, não sabem quais os direitos que tem em ser um cidadão. Portanto, é preciso pensar em um modo que os cidadãos sejam informados por estes direitos jurídicos e políticos.

A educação, a cidadania, o direito, a sociedade, a justiça e a democracia se vinculam entre si. O problema é como fazem, sobre quais fundamentos se define tal vínculo. Para alguns, por exemplo, educar para a cidadania significa formar indivíduos que conheçam seus direitos, seus deveres e suas obrigações; especialmente em capacitá-los para o exercício consciente da participação política. Para outros, formar cidadãos significa dotar aos indivíduos das competências necessárias para adaptar-se com as modificações que sofre o mundo produtivo, permitindo que eles contribuam ativamente para o crescimento econômico do país.

Portanto, o eleitor responsável, do consumidor inteligente e do trabalhador competitivo costuma ser as mais usadas para resumir o modelo de indivíduo que melhor sintetiza os atributos desejáveis do cidadão que a educação democrática deve (ou deveria) contribuir para formar.

Sendo assim, uma ação pedagógica destinada ao aprendizado da Constituição e das leis permitiria consolidar e desenvolver nos indivíduos a percepção de sua condição de cidadão. $\mathrm{O}$ exercício da cidadania se vincula, ao reconhecimento de certas responsabilidades derivadas de um conjunto de valores constitutivos daquilo que poderia definir-se como o campo da ética cidadã.

\section{Referências}

ALMEIDA, A.O. Gestão democrático-participativa na escola pública: breves considerações. Disponível em: <

http://www.google.com.br/url?sa=t\&rct=j\&q=\&esrc=s\&source=web\&cd=3\&ved=0CDcQFjA C\&url=http\%3A\%2F\%2Fwww.interativadesignba.com.br\%2FIII_SPSC\%2Farquivos\%2Fses 
sao5\%2F123.pdf\&ei=VG_6UvHpFNOukAeSj4DwCg\&usg=AFQjCNFhvCAGhLOukfxidg4 NeFKz_KlIdg>. Acesso em: 04 fev. 2014.

ARAUJO, Francisca Socorro. Sobre o conceito de cidadania e seus reflexos na escola. Disponível em: < http://www.infoescola.com/sociologia/cidadania-e-educacao/>. Acesso em: 04 fev. 2014.

BRASIL. Secretaria de Educação Fundamental. Parâmetros Curriculares Nacionais: apresentação dos Temas Transversais, Ética. vol. 10. Brasília: MEC/SEF, 1997.

BRASIL. Constituição da República Federativa do Brasil. Brasília, DF: Senado Federal, 1988.

Estatuto da Criança e do Adolescente, Lei no 8069 de 13 de julho de 1990.

Disponível em: http://www.planalto.gov.br/ccivil_03/Leis/L8069.htm Acesso em: 04 fev. 2014.

Lei de Diretrizes e Bases da Educação Nacional, nº 9394 de 20 de dezembro de 1996. Disponível em: http://www.planalto.gov.br/ccivil_03/Leis/L9394.htm. Acesso em: 06 fev. 2014.

Ministério da Educação. Secretaria de Educação Básica. Programa Ética e Cidadania - Construindo Valores na Escola e na Sociedade. Brasília: MEC/SEB, 2005. Disponível em: http://portal.mec.gov.br/seb/index.php?option=content\&task=view\&id=50 3\&Itemid=492. Acesso em: 03 fev. 2014.

Plano Nacional da Educação. Lei n 10.172 de 09 de janeiro de 2001. Disponível em: http://www.planalto.gov.br/ccivil_03/Leis/LEIS_2001/L10172.htm Acesso em 10.01.2010.

BUFFA, Ester; ARROYO, Miguel; NOSELLA, Paolo. Educação e Cidadania: Quem educa o cidadão? $10^{a}$ ed. São Paulo, Cortez, 2002. 95p.

CABRAL, Márcia Regina. Educação e Cidadania. 2008. Disponível em: < http://www.webartigos.com/artigos/educacao-e-cidadania/10791/>. Acesso em: 04 fev. 2014.

FREIRE, A. (Org.). Pedagogia dos sonhos possíveis. São Paulo: UNESP, 2002.

FREIRE, P. Educação e mudança. Rio de Janeiro: Paz e Terra, 1979. LIBÂNEO, J. Didática. São Paulo: Cortez, 1992.

GENTILI, Pablo; ALENCAR, Chico. Educar na esperança em tempos de desencanto. $3^{\text {a }}$ edição, Petrópolis, Vozes, 2003. 142 p.

WANDERLEY, Luiz Eduardo W. Educação para a cidadania. Horizonte, Belo Horizonte, v. 2, n. 4, 2004, p. 127-136. 